DOI 10.37882/2500-3682.2022.01.01

\title{
СМЫСЛОЖИЗНЕННЫЕ ОРИЕНТАЦИИ ПЕДАГОГИЧЕСКИХ РАБОТНИКОВ КАК ВОЗМОЖНЫЙ РЕСУРС АДАПТИВНОЙ ОБРАЗОВАТЕЛЬНОЙ СРЕДЫ
}

\section{LIFE-MEANING ORIENTATIONS OF TEACHING STAFF AS A POSSIBLE RESOURCE OF ADAPTIVE EDUCATIONAL ENVIRONMENT}

\author{
A. Kiseleva \\ M. Kuzmin \\ G. Starodubtseva
}

Summary: The article presents a study of the life-meaning orientations of modern teaching staff, considered as a possible resource of an adaptive educational environment. The obtained results allowed the authors to identify the features of the life-meaning orientations of teaching staff in general, as well as depending on the specialty. The study revealed the homogeneity of the levels of life-meaning orientations and values among teaching staff in general; a low level of expression of life-meaning orientations, as well as negative connections between life-meaning orientations and values. It is likely that teaching staff have a discrepancy between the declared values and a sense of the meaningfulness of their actions, their subjectivity in achieving them, which may pose a major threat to the formation of an adaptive educational environment.

Keywords: life-meaning orientations, value orientations, educational environment, teachers.
Киселева Анастасия Андреевна

Стариий методист, Институт развития образования Иркутской области nk160493@gmail.com

Кузьмин Михаил Юрьевич к.псх.н., Дочент, ФГБОУ ВО «Иркутский государственный университет» mirroy@mail.ru

Стародубцева Галина Александровна к.nсх.н., Доцент, Институт развития образования Иркутской области g.starodubceva@iro38.ru

Аннотация: В статье представлено исследование смысложизненных ориентаций современных педагогических работников, рассматриваемых как возможный ресурс адаптивной образовательной среды. Полученные результаты позволили авторам выявить особенности смысложизненных ориентаций педагогических работников в целом, а также в зависимости от специальности. В ходе исследования обнаружена гомогенность уровней смысложизненных ориентаций и ценностей у педагогических работников в целом; низкий уровень выраженности смысложизненных ориентаций, а также отрицательные связи между смысложизненными ориентациями и ценностями. Вероятно, у педагогических работников существует несоответствие между декларируемыми ценностями и ощущением осмысленности своих действий, своей субъектности в их достижении, что может представлять основную угрозу формированию адаптивной образовательной среды.

Ключевые слова: смысложизненные ориентации, ценностные ориентации, образовательная среда, педагоги.

педагогической деятельности, постольку она является фактором формирования адаптивной образовательной среды, предотвращающим возникновение деструктивных изменений в эмоциональном состоянии и личности педагога [13], и, как следствие, в личности учащихся [9]. Некоторые авторы считают, что система отношений и ценностей педагогов влияют на построение траектории взаимодействия с детьми и определяют поведение учителя [8].

Обозначая понятия «ценностные ориентации» и «смысложизненные ориентации», современные исследователи отмечают, что ценностные ориентации, определяющие жизненные цели человека, выражают то, что является для него наиболее важным и обладает для него личностным смыслом [29]. В то же время смысложизненные ориентации рассматриваются как результат осознания ценностей, целей и смысла собственной жизни. [14]. В ряде работ понятия «ценность» и «смысложизенная 
ориентация» рассматриваются как синонимы. Так, в понимании Б.С. Братуся, ценности - это осознанные и принятые человеком общие смыслы его жизни [4]. По мнению М.С. Яницкого, А.В. Серого, Ю.В. Пелех, ценностные ориентации отражают смысловую сторону направленности личности [29].

Зарубежные исследователи [30; 31; 33], занимаясь проблемой ценностей педагогов, утверждают, что последние оказывают большое влияние как на общение с учениками, так на формирование их ценностей (так называемая «скрытая педагогика»). Соответственно, необходимо стимулировать педагогов развивать свои собственные ценности и нормы, осознанные и выраженные посредством обучения [33]. При этом среди ценностей, необходимых для формирования адаптивной образовательной среды, выделяются демократические ценности [32], моральные ценности [31].

Таким образом, проблема ценностно-смысловой сферы педагогов как ресурса образовательной среды рассматривается и в отечественной, и в зарубежной психологии. При этом открытым остается вопрос о содержании смысложизненных ориентаций, непосредственно определяющих адаптивную образовательную среду. Если в зарубежных исследованиях называются ценности, необходимые для формирования такой среды, то в отечественной психологии таких исследований фактически не проводилось.

Данная статья предваряет исследование ценностных ориентаций современных педагогических работников, необходимых для формирования адаптивной образовательной среды. На первом этапе мы поставили целью выявить особенности смысложизненных ориентаций педагогических работников в целом, а так же изучить, какие из них им присущи в зависимости от специальности. Это позволит нам в дальнейшем связать данные смысложизненные ориентации с компонентами образовательной среды.

\section{База и методы исследования}

Исследование проводилось на базе ГАУ ДПО «ИРО» (г. Иркутск) в период с февраля по апрель 2021 г. Выбор- ку составили 402 педагогических работников женского пола образовательных учреждений в возрасте от 21 года до 58 лет различных специальностей.

Для изучения смысложизненных ориентаций были использованы такие методики как «Диагностика реальной структуры ценностных ориентаций личности» (С.С. Бубнова) [3], «Тест смысложизненных ориентаций» (Д.А. Леонтьев) [15].

Обработка полученных данных осуществлялась с использованием критерии корреляции Спирмена и критерия Стьюдента. Расчеты проводились в программе IBM SPSS 21.0.

\section{Результаты}

Основу выборки педагогических работников, принявших участие в исследовании, составили учителя школ (35,6\%), воспитатели (30,6\%), психологи (14,4\%), прочий персонал ДОУ (13,2\%), администрация (6,2\%), т.е. группы педагогических работников, непосредственно взаимодействующие с учащимися и воспитанниками, непосредственно включенные в формирование адаптивной образовательной среды.

На первом этапе мы изучили особенности смысложизненных ориентаций педагогических работников, используя методику «Тест смысложизненных ориентаций» (табл. 1.).

Полученные результаты мы сравнили с нормативными, предложенными Д.А. Леонтьевым в тексте его методики. В целом, результаты педагогических работников оказываются ниже нормативов, принятых для представителей того же пола в оригинальном исследовании Д.А. Леонтьева. Особенно низкими оказываются результаты по шкале «Локус контроль - жизнь». Данная шкала характеризует уверенность в том, что человеку дано контролировать свою жизнь, свободно принимать решения и воплощать их. Низкие баллы по данной шкале свидетельствуют о фатализме, убежденности в том, что жизнь человека неподвластна сознательному контролю, что свобода выбора иллюзорна и бессмысленно что-либо загадывать на будущее.

Таблица 1.

Полученные результаты по методике «Тест смысложизненных ориентаций» (Д.А. Леонтьев) (средние значения)

\begin{tabular}{|l|c|c|c|c|c|c|}
\hline \multicolumn{1}{|c|}{ Шкалы } & Цели & Процесс & Результат & Локус контроля Я & Локус контроля - жизнь & ОЖ \\
\hline М (педагогические работники) & 26,84 & 26,16 & 20,60 & 15,69 & 18,70 & 107,98 \\
\hline б (педагогические работники) & 3,052 & 2,383 & 2,245 & 1,587 & 5,073 & 5,221 \\
\hline М (Д.А. Леонтьев) & 29,38 & 28,80 & 23,30 & 18,58 & 28,70 & 95,76 \\
\hline$\Sigma$ (Д.А. Леонтьев) & 6,24 & 6,14 & 4,95 & 4,30 & 6,10 & 16,54 \\
\hline
\end{tabular}


Соответственно, можно предположить, что для современных педагогических работников не характерны представления о свободе личности в принимаемых ею решениях.

При этом мы не обнаружили никаких значимых различий в выраженности шкал методики «Тест смысложизненных ориентаций» у представителей различных направлений работы в ДОУ и СОШ. Результаты педагогических работников, как тех, кто относится к руководящему составу, так и всех остальных, оказались достаточно гомогенны: не были обнаружены значимые различия между руководящим составом, работниками дополнительного образования и педагогами-психологами.

Таким образом, можно сделать следующий вывод. По сравнению с результатами Д.А. Леонтьева, которые относятся к женской русскоязычной выборке в целом, результаты педагогических работников оказываются ниже по всем основным шкалам методики «Тест смысложизненных ориентаций». Особенно низок результат по шкале «Локус контроль - Жизнь». При этом мы не обнаружили никаких значимых различий в выраженности шкал методики СЖО у представителей различных направлений работы в ДОУ и СОШ.

С целью уточнения полученных данных, мы изучили ценностно-смысловую сферу педагогических работников при помощи методики «Диагностика реальной структуры ценностных ориентаций личности» С.С. Бубновой.

В целом, по данной методике наиболее высокие результаты педагогические работники продемонстрировали в отношении ценностей «Помощь, милосердие к другим людям» (4.14), «Познание нового в мире» (4.06) и «Здоровье» (3.86). Ниже всего выражены ценности «Любовь» (1.64) и «Поиск и наслаждение прекрасным» (2.69).

При этом мы постарались дифференцировать ценности педагогических работников в зависимости от их специализации. Это было вызвано уже упомянутым ранее предположением, что вклад педагогических работников различных специальностей в формирование образовательной среды будет так же различным.

В таблице 2 представлены средние значения предпочтения тех или иных ценностей специалистов, занятых в сопровождении, воспитании и обучении детей (табл. 2).

Как и в случае с методикой «Тест смысложизненных ориентаций», оказалось, что ценности педагогических работников гомогенны: нет определенных значимых различий в выраженности тех или иных из них у представителей различных направлений работы. Определенно можно говорить, что у воспитателей ДОУ более чем у учителей и педагогов-психологов выражена ценность «Любовь» $(t=2,112, p=0,036)$ и «Социальная активность для достижения позитивных изменений в обществе» $(\mathrm{t}=2,357, \mathrm{p}=0,019)$. Кроме того, оказалось, что у сотрудников администрации (директоров, заведующих ДОУ и завучей) больше выражена ценность «Высокий социальный статус и управление людьми» $(\mathrm{t}=2,147, \mathrm{p}=0,04)$.

В целом, учитывая, что учителя и воспитатели ДОУ составляют основу данной выборки, можно высказать ряд предположений. Специфика труда воспитателей ДОУ с учетом возрастных особенностей воспитанников, с которыми они работают, предполагает безусловное принятие последних и, как следствие, большую к ним любовь. Учитель в школе ввиду как возрастных особенностей учащихся, так и требований ФГОС, оказывается более требовательным. Это может объяснить, почему у воспитателей ДОУ выше ценность Любви, чем у их коллег - однако не может объяснить, почему соответствующая ценность оказывается также низкой относительно других, как и у остальных педагогических работников в целом.

Большая выраженность ценности «Социальная активность для достижения позитивных изменений в обществе» у воспитателей ДОУ по сравнению с учителями может быть связана с тем, что воспитатели ДОУ в меньшей степени «связаны» существующими нормами и требованиями к организации образовательного процесса. Большая выраженность ценности «Высокий социальный статус и управление людьми» у сотрудников администрации выглядит закономерной.

Наконец, мы проанализировали специфику связей различных смысложизненных ориентаций и ценностей на всей выборке испытуемых (табл. 3).

В целом, связи оказываются недостаточно тесными и преимущественно отрицательными. Также отметим, что среди ценностей, наиболее выраженных у педагогических работников, корреляции обнаружены только с одной из них - ценности «Помощь и милосердие к другим людям».

Выраженность интегральной шкалы «ОЖ» оказывается отрицательно связанной не только с ценностью «Высокое материальное положение и благосостояние» $(r=-0,198, p<0,01)$, но и «Помощь и милосердие к другим людям» $(r=-0,197, p<0,01)$. Шкала «Локус-контроля Я» оказывается отрицательно связанной и со шкалой «Приятное времяпрепровождение, отдых» и со шкалами «Помощь и милосердие к другим людям» и «Общение». Только шкалы «Цель» и «Процесс» преимущественно положительно связаны с ценностными ориентациями.

Отдельно обращает на себя внимание шкала «Локус-контроль - жизнь», которая, как мы отмечали выше, 
наиболее низко выражена у педагогических работников по сравнению с результатами женской выборки по методике «Тест смысложизненных ориентаций» в целом. Выделяется она, с одной стороны, обилием корреляций, а, с другой, их сравнительной частотой. Так, данная шкала оказывается положительно связанной только со шка- лой «Приятное времяпрепровождение, отдых» $(r=0,193$, $\mathrm{p}<0,01)$, а со всеми другими ценностями она связана отрицательно, причем для ценности «Помощь и милосердие к другим людям», наиболее выраженной у педагогических работников, эта связь очень высока ( $r=0,262$, $\mathrm{p}<0,01)$. Получается, что у современных педагогических

Таблица 2.

Полученные результаты по методике «Диагностика реальной структуры ценностных ориентаций личности» (С.С. Бубнова) педагогических работников разной специальности (средние значения)

\begin{tabular}{|c|c|c|c|c|c|c|c|c|c|c|c|c|}
\hline \multicolumn{2}{|c|}{$\begin{array}{c}\text { Группы } \\
\text { педагогических } \\
\text { работников }\end{array}$} & 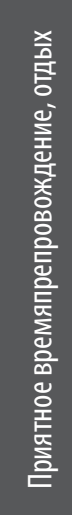 & 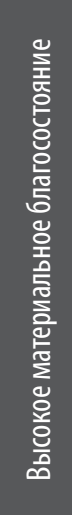 & 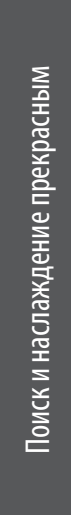 & 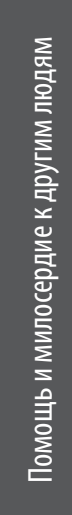 & $\begin{array}{l}\text { 0े } \\
\text { 옫 }\end{array}$ & 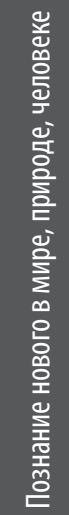 & 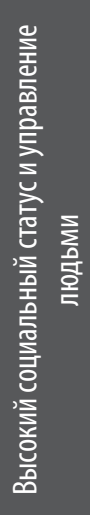 & 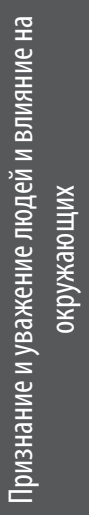 & 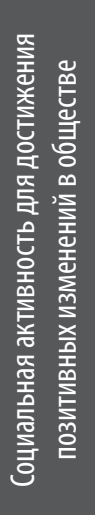 & 壱 & $\begin{array}{l}\text { गे } \\
\text { 0े } \\
\text { 응 } \\
\text { m }\end{array}$ \\
\hline \multirow{2}{*}{$\begin{array}{l}\text { Общие } \\
\text { резуль- } \\
\text { таты }\end{array}$} & M & 3,58 & 3,51 & 2,69 & 4,14 & 1,64 & 4,06 & 3,61 & 2,82 & 3,31 & 3,43 & 3,86 \\
\hline & SD & 1,13 & 1,32 & 1,06 & 1,06 & 1,10 & 1,05 & 0,84 & 0,96 & 1,05 & 1,03 & 0,74 \\
\hline \multirow{2}{*}{$\begin{array}{l}\text { воспита- } \\
\text { тели ДОУ }\end{array}$} & M & 3,7 & 3,6 & 2,7 & 4 & 1,8 & 4,2 & 3,6 & 2,7 & 3,5 & 3,6 & 3,9 \\
\hline & SD & 1,1 & 1,3 & 1,1 & 1 & 1,2 & 1 & 0,8 & 0,9 & 1 & 1,1 & 0,7 \\
\hline \multirow{2}{*}{$\begin{array}{l}\text { админи- } \\
\text { страция }\end{array}$} & M & 3,8 & 3,6 & 3 & 4,4 & 1,7 & 4 & 4 & 3 & 3,4 & 3,3 & 4 \\
\hline & SD & 1,1 & 1,1 & 1,1 & 1,2 & 1,1 & 1,1 & 1,2 & 1 & 1 & 1,1 & 0,8 \\
\hline \multirow{2}{*}{$\begin{array}{l}\text { педагоги } \\
\text { доп. обра- } \\
\text { зования }\end{array}$} & $M$ & 3,2 & 3,2 & 2,6 & 4,2 & 1,5 & 3,8 & 3,5 & 2,8 & 3,2 & 3,2 & 3,7 \\
\hline & SD & 1 & 1,3 & 1,3 & 1,3 & 1 & 1,1 & 0,9 & 1,1 & 1 & 1 & 0,7 \\
\hline \multirow[t]{2}{*}{ учителя } & M & 3,6 & 3,5 & 2,7 & 4,1 & 1,5 & 4,1 & 3,6 & 2,9 & 3,2 & 3,5 & 3,9 \\
\hline & SD & 1,1 & 1,3 & 1 & 1 & 1,1 & 1,1 & 0,8 & 0,9 & 1,1 & 1,1 & 0,7 \\
\hline \multirow{2}{*}{$\begin{array}{l}\text { психологи, } \\
\text { логопеды }\end{array}$} & M & 3,4 & 3,7 & 2,7 & 4,3 & 1,6 & 4 & 3,6 & 2,8 & 3,3 & 3,3 & 3,9 \\
\hline & SD & 1,2 & 1,3 & 0,9 & 1 & 1 & 1 & 0,9 & 1 & 0,9 & 0,9 & 0,8 \\
\hline
\end{tabular}

Таблица 3.

Специфика связей полученных результатов по методике «Тест смысложизненных ориентаций» (Д.А. Леонтьев) и по методике «Диагностика реальной структуры ценностных ориентаций личности» (С.С. Бубнова)

\begin{tabular}{|c|c|c|c|c|c|}
\hline Шкалы & Цели & Процесс & Локус контроля Я & Локус контроля - жизнь & OЖ \\
\hline Приятное времяпрепровождение, отдых &,$- 109^{*}$ & - &,$- 145^{* *}$ &, $193^{* *}$ & - \\
\hline Высокое материальное благосостояние & - & - & - &,$- 109^{*}$ &,$- 198^{* *}$ \\
\hline Поиск и наслаждение прекрасным &, $115^{*}$ & - & - &,$- 186^{* *}$ & - \\
\hline Помощь и милосердие к другим людям &, $134^{* *}$ & - &,$- 184^{* *}$ &,$- 262^{* *}$ &,$- 197^{* *}$ \\
\hline Высокий социальный статус и управление людьми &, $130^{* *}$ &, $111^{*}$ & &,$- 101^{*}$ & - \\
\hline Общение & - & - &,$- 121^{*}$ & - & - \\
\hline \multicolumn{6}{|l|}{ *. Корреляция значима на уровне 0,05 (двухсторонняя). } \\
\hline
\end{tabular}


работников наблюдается некий конфликт между, с одной стороны, выраженностью определенных ценностей и, с другой стороны, фатализмом, убежденностью в том, что жизнь человека неподвластна сознательному контролю. Интерпретируя корреляции, можно сделать вывод, что современные педагоги на уровне целей способны строить проекты относительно своего социального статуса, помощи другим и наслаждения прекрасным однако при этом не чувствуют возможности контролировать выполнение этих целей. В этом несоответствии между декларируемыми ценностями и ощущением осмысленности своих действий, своей субъектности в их достижении, и можно видеть, с одной стороны, специфику ценностно-смысловой сферы педагогических работников, а, с другой, основную угрозу формированию адаптивной образовательной среды. При сравнительно низком уровне развития смысложизненных ориентаций декларирование определенных ценностей оказывается просто мало к чему обязывающем «заявлением о намерении», реализация которого зависит от каких-то других сил, а не от самого педагога.

\section{Обсужкение результатов}

В ходе данного исследования мы обнаружили, с одной стороны, достаточную гомогенность уровней смысложизненных ориентаций и ценностей у педагогических работников вне зависимости от их специальности, с другой стороны, низкий уровень выраженности смысложизненных ориентаций и, наконец, преимущественно отрицательные связи между смысложизненными ориентациями и ценностями.

Сопоставляя полученные результаты с результатами других авторов, отметим следующее. Хотя проблема смысложизненных ориентаций педагогов рассматривалась многими отечественными исследователями [1; $10 ; 11 ; 16 ; 18 ; 19 ; 21-25 ; 28]$ с различных сторон (в зависимости от возраста [28], профессионального стажа [1; $11 ; 21 ; 25]$, профессионального выгорания [19; 25], профессионального кризиса [23] или в сравнении со смысложизненными ориентациями представителей других специальностей [11]), однако зачастую не приводились сами результаты. Мы можем сравнить полученные нами данные по методике «Тест смысложизненных ориентаций» с подробными результатами, которые приводит У.М. Асадулаева и А.С. Дамадаевой - согласно им, смысложизненные ориентации педагогических работников значимо выше полученных нами результатов [1]. Полученные расхождения можно объяснить спецификой ситуации, в рамках которой мы проводили данное исследование - эпидемия COVID-19. Однако и в результатах У.М. Асадулаевой можно обратить внимание, что выраженность шкалы Локус-контроль - Жизнь по основным возрастным группам оказывается ниже результатов, приводимы Д.А. Леонтьевым. Таким образом, и при срав- нении наших данных с другими исследованиями можно констатировать сравнительно более высокий уровень фатализма педагогических работников современных образовательных организаций.

Мы не обнаружили вслед за С.В. Дубровиной и ее коллегами, что смысложизненные ориентации педагогических работников характеризует наличие четкой цели в жизни, построение конкретных жизненных планов, убеждение, что человеку дано контролировать свою жизнь, свободно принимать решения и воплощать их [8; 10]. Однако ими приводятся только корреляционные связи.

В ряде исследований были выявлены и противоречия, связанные с особенностями смысложизненных ориентаций педагогических работников в зависимости от их профессионального стажа $[11 ; 16 ; 21]$. Однако мы не рассматривали стаж как один из коррелятов смысложизненных ориентаций педагогических работников, что планируется исправить в следующих исследованиях.

Также стоит отметить, что существуют исследования, связывающие смысложизненные ориентации и специфику работы педагога - дистанционная она или нет [2], совместное обучение или нет [10]. Мы не рассматривали данные корреляты, ограничившись лишь тем, находится ли данное учебное заведение в городской или сельской местности. В последнем случае мы не получили какихлибо значимых различий ни по одной шкале методики.

\section{Зак^ючение}

В ходе данного исследования мы обнаружили, с одной стороны, достаточную гомогенность уровней смысложизненных ориентаций и ценностей у педагогических работников вне зависимости от их специальности, с другой стороны, низкий уровень выраженности смысложизненных ориентаций и, наконец, преимущественно отрицательные связи между смысложизненными ориентациями и ценностями. Мы интерпретировали это в том смысле, что существует несоответствие между декларируемыми ценностями и ощущением осмысленности своих действий, своей субъектности в их достижении. Это может представлять основную угрозу формированию адаптивной образовательной среды.

При этом ограничением данного исследования является период его проведения - ситуация эпидемии COVID-19. Возможно, именно он является причиной повышения уровня фатализма среди педагогических работников (в сравнимых исследованиях соответствующий показатель методики Д.А. Леонтьева был ниже). Мы планируем, связывая в дальнейшем смысложизненные ориентации и конкретные параметры образовательной среды, нивелировать влияние данного фактора. 


\section{ЛИТЕРАТУРА}

1. Асадулаева У.М., Дамадаева А.С. Психологические особенности смысложизненных ориентаций учителей на разных этапах профессиональной деятельности // Мир образования - образование в мире. - 2016. - № 2 (62). - С. 124-129.

2. Бакаева И.А., Ванжа Л.Н. Исследование личностного профиля педагога дистанционного образования // Российский психологический журнал. - 2015. Т. 12. № 3. - С. 16-32.

3. Бубнова С.С. Методика диагностики индивидуальной структуры ценностных ориентаций личности // Методы психологической диагностики. М.: Изд-во ИПРАН, 1994. Вып. 2.

4. Братусь Б.С. К изучению смысловой сферы личности // Вестн. Моск. ун-та. - 2001. - Сер. 14. Психология. - № 2. - С. 46 - 56.

5. Васютенкова И.В. Профессионально-образовательная среда как фактор развития компетентности педагога по обеспечению психологически безопасной и комфортной образовательной среды // Герценовские чтения: психологические исследования в образовании. - 2019. - № 2. - С. 767-774.

6. Гарибзянова Е.Е. Исследование понятия образовательной среды // Инновационная наука. - 2016. - № 1-2 (13). - С. 156-158.

7. Гришина Е.В. Психологические характеристики образовательной среды и антивитальные переживания подростков // Народное образование. -2016. № 4-5 (1456). - С. 215-218.

8. Дубровина С.В., Дрейзин И.В. Взаимосвязь внутренних ресурсов личности и удовлетворенности качеством жизни у педагогов // Теория и практика общественного развития. - 2015. - № 21. - С. 335-337.

9. иселева А.А., Кузьмин М.Ю., Козлов В.В. Особенности копинг-стратегий педагогических работников различного стажа и специальности // Интеграция образования. - 2020. - Т. 24, № 4. - С. 641-655.

10. Косикова Л.В. Особенности смысложизненых и ценностных ориентаций педагогов, работающих в классах совместного обучения // Проблемы современного педагогического образования. - 2017. - № 57-8. - С. 288-294.

11. Котова С.А. Особенности личностных характеристик и смысложизненных ориентаций педагогов с разным стажем работы // Известия Российского государственного педагогического университета им. А.И. Герцена. - 2011. - № 139. - С. 25-34.

12. Кошечкина Т.В. Особенности коммуникативного развития ребёнка-инвалида раннего и дошкольного возраста в семейной среде и среде образовательной организации // Мастер-класс. - 2017. - № 1. - С. 48-51.

13. Курапова И.А. Нравственно-ценностная регуляция эмоционального выгорания в профессиональной деятельности (на примере педагогов средней и высшей школы): автореф. на соиск. ученой степ. канд. психол. наук: 19.00.03. М., 2009. 25 с.

14. Леонтьев Д.А. Психология смысла: природа, строение и динамика смысловой реальности / Д.А. Леонтьев. 2-е, испр. изд. М.: Смысл, 2003.487 с.

15. Леонтьев Д.А. Тест смысложизненных ориентаций (СЖО) / Д.А. Леонтьев. 2-е изд. М.: Смысл, Серия: Психодиагностическая серия, 2000.18 с.

16. Марченко А.В. К вопросу о смысложизненных ориентациях представителей педагогических профессий // Матрица научного познания. - 2021. - № 2-1. C. 202-205.

17. Морошкина А.Н. Образовательная среда: понятие, сущность, характеристики // Инновационная наука. - 2016. - № 1-2 (13). - С. 195-198.

18. Наличаева С.А. Особенности ценностно-смысловой и мотивационной сфер педагогов средней и высшей школы // Известия Южного федерального университета. Педагогические науки. - 2011. - № 1. - С. 127-136.

19. Наличаева С.А. Особенности ценностно-смысловой сферы педагогов с различными уровнями профессионального выгорания // Вестник Московского государственного областного университета. Серия: Психологические науки. - 2010. - № 3. - С. 111-118.

20. Панасенко Х.А. Безопасность школьной образовательной среды в контексте отношений в подростковом и старшем школьном возрасте // Достижения вузовской науки. - 2016. - № 25-1. - С. 152-157.

21. Сабирова Р.Ш., Ширинбекова Ж. Психологические аспекты взаимосвязи ценностно-смысловой сферы и профессионального роста педагогов: современное образовательное пространство // Международный журнал прикладных и фундаментальных исследований. - 2016. - № 4-5. - С. $1010-1014$.

22. Садовникова Н.0., Мирзаахмедов А.М. Актуальные смысловые состояния педагогов, переживающих профессиональный кризис личности // 0бразование и наука. - 2019. - Т. 21. № 2. - С. 113-131.

23. Садовникова Н.О., Сергеева Т.Б. Смысловая саморегуляция в контексте переживания педагогами профессионального кризиса личности // Научный диалог. - 2018. - № 1. - С. 265-277.

24. Садовникова Н.0., Сергеева Т.Б. Смысложизненные ориентации педагогов в ситуации профессионального кризиса личности // Научный диалог. - 2016. № 9 (57). - С. 297-310.

25. Сильченко С.С. Смысложизненные ориентации педагогических работников с различным уровнем профессионального выгорания // Тенденции развития науки и образования. - 2020. -№ 62-20. - С. 50-56.

26. Скрипниченко В.В. Различные подходы к характеристике адаптивной образовательной среды // Гуманитарные и социально-экономические науки. 2006. - № 5 (24). - C. 215-218.

27. Стародубцев В.А. Создание персонализированных образовательных сред // 0бразовательные технологии. - 2016. - № 2. - С. 35-50.

28. Шмагина Ю.Д. Особенности смысложизненных ориентаций педагогов дополнительного образования зрелого возраста // Глобальный научный потенциал. - 2017. - № 10 (79). - С. 99-101.

29. Яницкий М.С., Серый А.В., Пелех Ю.В. Ценностно-смысловая парадигма как основа постнеклассической педагогической психологии // Философия об- 
разования. - 2013. - № 1. - С. 175-186.

30. Fischer E., Hänze M. (2020) How do university teachers' values and beliefs affect their teaching? Educational Psychology An International Journal of Experimental Educational Psychology, 40(3), 296-317. https://doi.org/10.1080/01443410.2019.1675867

31. Pantić, N., Wubbels, T. (2012). Teachers' moral values and their interpersonal relationships with students and cultural competence. Teaching and Teacher Education, 28(3), 451-460. doi:10.1016/j.tate.2011.11.011

32. Selvi K. (2006). Developing a teacher trainees' democratic values scale: validity and reliability analyses. Social Behavior and Personality An International Journal, 34(9), 1171-1178. doi: 10.2224/sbp.2006.34.9.1171

33. Willemse M., Lunenberg M., Korthagen F. (2008) The moral aspects of teacher educators' practices. Journal of Moral Education, 37:4, 445-466. doi: $10.1080 / 03057240802399269$

\section{(๐ Киселева Анастасия Андреевна (nk160493@gmail.com), Кузьмин Михаил Юрьевич (mirroy@mail.ru), Стародубцева Галина Александровна (g.starodubceva@iro38.ru). \\ Журнал «Современная наука: актуальные проблемы теории и практики»}

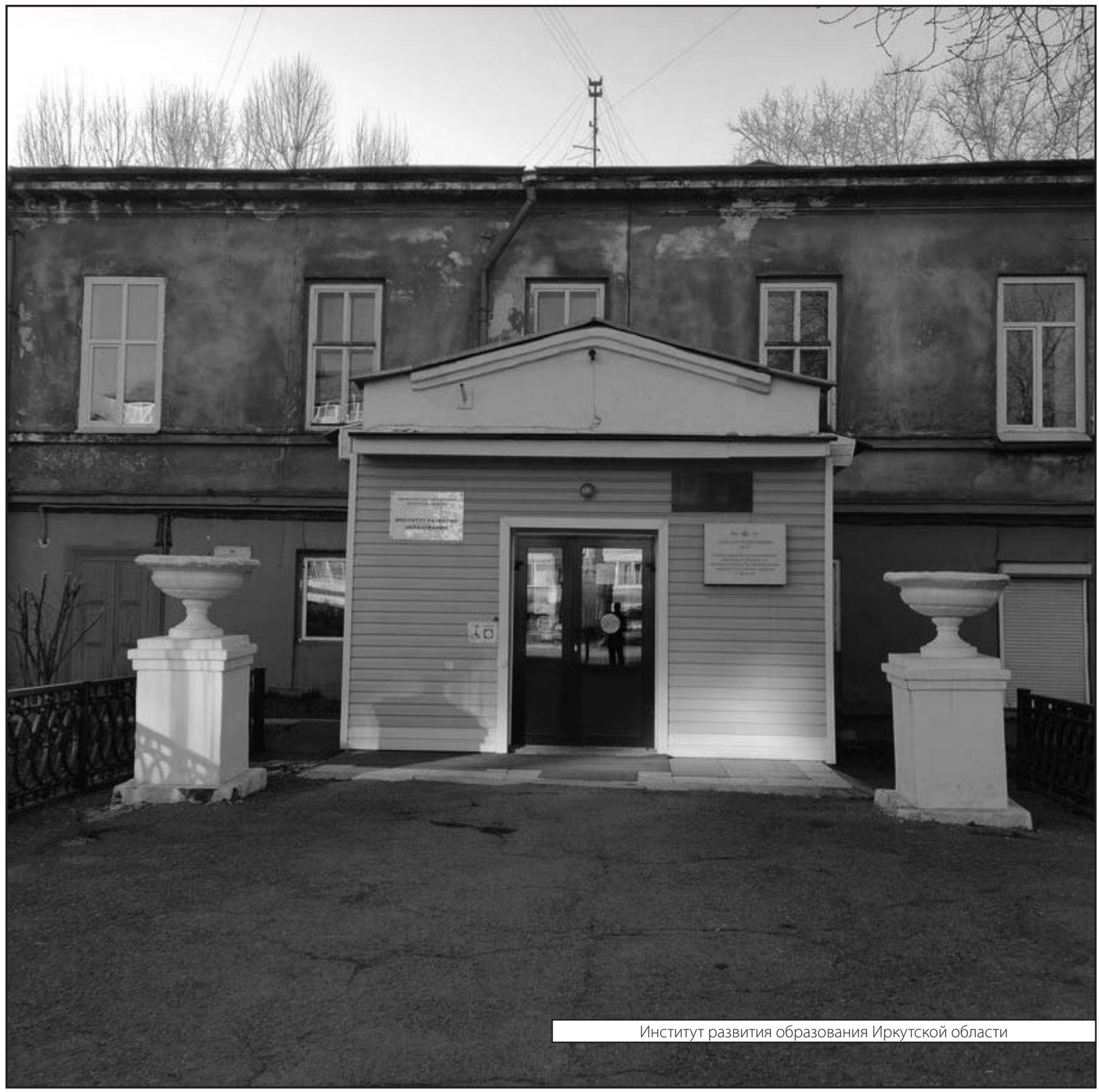

